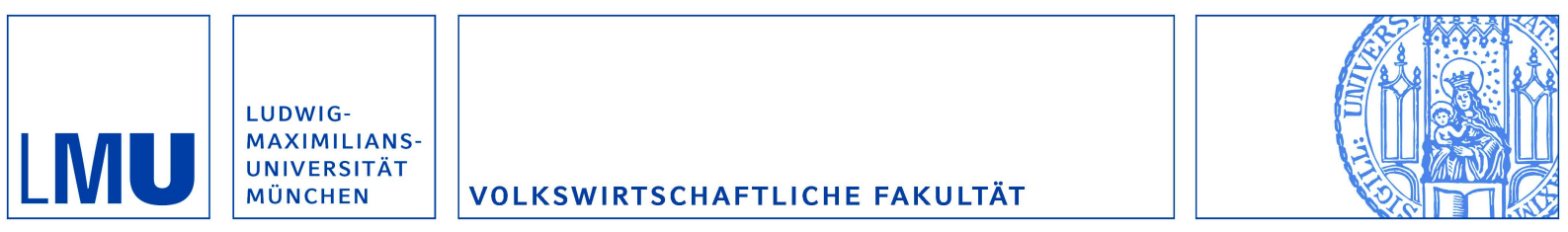

Müller, Thomas:

Analyzing Modes of Foreign Entry

Munich Discussion Paper No. 2001-1

Department of Economics

University of Munich

Volkswirtschaftliche Fakultät

Ludwig-Maximilians-Universität München

Online at https://doi.org/10.5282/ubm/epub. 13 


\title{
Analyzing Modes of Foreign Entry: Greenfield Investment versus Acquisition*
}

\author{
Thomas Müller ${ }^{\dagger}$ \\ University of Munich
}

December 2000

\begin{abstract}
This paper studies the entry decision of a multinational enterprise into a foreign market. Two alternative entry modes for a foreign direct investment are considered: Greenfield investment versus acquisition. In contrast to existing approaches, the acquisition price and the profits under both entry modes are endogenously determined. Interestingly, we find that the optimal entry mode decision is affected by the competition intensity in the market in a non-monotonic way. When markets are very much or very little competitive, greenfield investment is the optimal entry mode, while for intermediate values it is acquisition.
\end{abstract}

JEL-classification numbers: D43, F21, F23, L13, P31.

Keywords: Foreign direct investment, multinational enterprise, greenfield investment, acquisition, transition economies.

${ }^{*}$ I would like to thank Monika Schnitzer, Dalia Marin and Björn Achter for helpful comments and suggestions. Financial support through Deutsche Forschungsgemeinschaft grant Schn 422/2-1 is gratefully acknowledged.

†Department of Economics, University of Munich, Akademiestr. 1/III, 80799 Munich, Germany, Tel.: +49-89-2180 2766, Fax.: +49-89-2180 2767, e-mail: Th.Mueller@lrz.unimuenchen.de 


\section{Introduction}

A multinational enterprise (MNE) considering entry into a foreign market faces two fundamental decisions. First, it has to choose the level of control over its local engagement. Equity-based entry could take the form of partially owned subsidiaries, as in joint ventures, or wholly owned subsidiaries, while non-equity entry would be licensing for example. Second, the MNE has to decide which mode of foreign entry to carry out. It can choose between the acquisition of an existing company or setting up a new venture via greenfield investment. Why would a multinational firm choose to enter one market via acquisition and another one through greenfield investment, while in principle for either market both alternatives are present?

This paper contributes to answering this question by providing a simple model to analyze determinants of the optimal entry mode. For this purpose we consider the decision to enter a market either via a greenfield investment or the acquisition of a single local competitor. While a general analysis of this strategic choice is provided, the specifications of the model especially allow us to apply its implications on the decision to enter a market in Central and Eastern Europe (CEE).

Most of the literature on foreign entry has focused on the first decision in considering the choice of ownership type between licensing, a wholly owned subsidiary, and a joint venture. These modes of entry differ considerably in their level of control, resource commitment, and risk. Anderson and Gatignon [1986], for example, analyze the tradeoff between control and the cost of resource commitment in a transaction cost framework. They argue that a greater level of control is more efficient for highly transaction-specific assets. Hill, Hwang and Kim [1990] present a wider approach which additionally takes into account global strategies of the MNE and the risk of dissemination of firm specific knowledge as factors influencing the control decision. Firms will prefer high control entry modes if they persue global strategies or possess a highly firm-specific know-how.

Relatively few studies have addressed the choice between greenfield investment and acquisition as modes of foreign entry. Empirically a variety of potential factors influencing the choice of entry mode have been studied. 
Kogut and Singh [1988], for example, study the influence of cultural distance on the choice between greenfield investment, acquisition and joint venture. The greater the cultural distance between the country of the investor and the country of entry, the more likely a firm will choose a joint venture or a greenfield investment over an acquisition. Other work considers additional firm-specific factors like international experience, firm size or R\&D. Caves and Mehra [1986] and Zejan [1990] find evidence that large and diversified companies prefer acquisition. Besides that acquisition is favored for entry into rapidly growing or very slow growing markets. Hennart and Park [1993] and Andersson and Svensson [1994] show that firms with higher R\&D intensity are more likely to choose greenfield investment.

Focusing on the specific conditions in transition economies Estrin, Hughes and Todd [1997] and Meyer [1998] empirically analyze the choices of ownership form and mode of entry into CEE. Estrin et al. [1997] find that most of the MNEs in their sample aimed to achieve 100 per cent ownership even if initially, e.g. for political reasons, not possible. Meyer [1998] tests a number of hypotheses for CEE entry, which are based on previous work in the international business literature. Surprisingly, he finds that entry into fastgrowing industries takes place via wholly owned greenfield investments, but not via acquisition. This is in contrast to the well known argument that a speedy entry, which is assumed important in fast-growing industries, can be achieved by acquisition and not via greenfield investment. It also contrasts the empirical findings by Caves and Mehra [1986] for US entry. Therefore, it suggests that industrial growth in transition economies creates specific conditions for competition that are different from other markets. The study also shows that greenfield investment is the most common mode of entry into CEE, accounting for more than 50 per cent of all projects in the sample. This is particularly surprising in the light of a worldwide trend towards acquisition and it underlines the need for a theoretical analysis. ${ }^{1}$

There only exist few theoretical approaches to the choice of foreign entry. Horn and Persson [2001a] analyze the equilibrium market structure in

\footnotetext{
${ }^{1}$ Mergers and acquisitions (M\&A) constitute an important mode of entry and their importance has increased over time (UNCTAD [2000]).
} 
an international oligopoly and focus on the question under which circumstances cross-border M\&A or domestic M\&A evolve. ${ }^{2}$ They do not, however, consider greenfield investment as an alternative mode of entry. Buckley and Casson [1998] analyze the choice among a variety of alternative entry modes. One important conclusion is that the market structure as well as the strength of competition in the market each have a crucial impact on the entry decision. Entry through greenfield investment contributes to the local capacity and intensifies competition, while acquisition entry does not. The existence of a high cost of competition associated with high monopoly rents makes acquisition favorable over greenfield investment. A highly specific production technology of the entrant resulting in higher adaptation costs, on the other hand, discourages acquisition and favors greenfield investment.

Görg [2000] builds on their approach in analyzing the effect of market structure on the choice between greenfield investment and acquisition in a Cournot-type setting. He shows that in general acquisition may be the prefered mode of entry, while only with a high cost of adaptation greenfield investment may be an optimal choice.

While Buckley and Casson [1998] determine market structure and strength of competition as important factors, they are not able to specify exactly how these factors affect the entry mode decision. In contrast to their approach the present model does so. We study the choice of entry mode of a MNE between setting up a new venture via greenfield investment or acquisition of the single local competitor. A greenfield investment enables the MNE to specify the subsidiary according to its technological capabilities, while acquisition allows at first only to use the given facilities. In the model presented below this fact is reflected in that the MNE possesses a superior technology, but can only make use of it when entering via greenfield. In case of acquisition it is restricted to the acquired firms technological capabilities. After the acquisition of the only competitor the MNE can act as a monopolist, while greenfield investment in general leads to a competitive situation. In addition to the endogenous effect of the market structure associated with the entry mode, the influence of an exogenous change in the competition intensity on

\footnotetext{
${ }^{2}$ See Horn and Persson [2001b] for a game-theoretic analysis of merger formation.
} 
the entry decision is analyzed. Contrasting Buckley and Casson [1998] or Görg [2000], we derive the acquisition price for an existing domestic firm as well as the profits for the alternative entry modes endogenously. These values obviously depend on the market structure, the competition intensity in the market and differentials in the production cost of the competing firms.

The effects of the different exogenous variables defined in the model on the entry decision are analyzed in detail. Increasing the investment cost of greenfield entry obviously makes acquisition more attractive. We show that this effect only holds up to a certain amount. If it gets too large, however, acquisition becomes unattractive and no entry will be an optimal choice. A higher technological backwardness of the domestic firm leads to a higher profit for the MNE in competition, a lower acquisition price and a lower monopoly profit for acquisition entry. Whether or not one of these effects dominates is a priori not clear. But we can show that greenfield investment is the optimal mode of entry only if the technological gap between the competitors is sufficiently large. Surprisingly, we furthermore find that the competition intensity within a market can influence the choice of entry mode in a non-monotonic fashion. When the market is very much or very little competitive, greenfield investment is the optimal entry mode, while for intermediate values it is acquisition.

With respect to the unusual empirical observations of entry mode decisions into countries in Central and Eastern Europe, the results presented in the model have some explanatory power. As the analysis shows greenfield investment is the optimal mode of entry only if the technological gap between the domestic firm and the MNE is sufficiently large. This is certainly the case in many markets in CEE, and may explain, why entry into these countries foremost takes place via greenfield investment - in opposition to the worldwide trend. Moreover, it is observed that entry into fast-growing industries surprisingly takes place via greenfield investment, but not via acquisition. Since one can associate fast-growing industries with less intense competition the model exactly predicts that greenfield investment is the optimal mode of entry in this situation.

The rest of this paper is organized as follows. The next section sets up 
the model. Section 3 considers the decision between greenfield investment and acquisition and presents the main results. Section 4 discusses some of the empirical observations and concludes.

\section{The Model}

In this section, we develop a theoretical framework to analyze the choice of entry mode for a multinational enterprise entering into a foreign country. Therefore, the focus is on the second decision a MNE faces, while 100 per cent ownership is assumed to be the desired level of control. We consider a model of horizontal product differentiation à la Hotelling [1929] with firms competing in prices. ${ }^{3}$ Consumers are assumed to be uniformly distributed along the unit interval $[0,1]$ with density 1 . Thus, the total number of consumers is equal to 1.

The model consists of two periods. In period 1, the domestic firm 1 located at $x=0$ serves (at least part of) the market. The foreign firm 2 considers whether or not to enter the market and, in case of entry, which entry mode to employ. The market is assumed to be stable in the sense that firm 1 cannot adopt a different production technology or set up a new venture and there is no other potential entrant besides firm 2. To enter the market firm 2 can either acquire firm 1 at location $x=0$ or set up a new venture at $x=1$ through a greenfield investment. In period 2, firms simultaneously compete in prices, when firm 2 entered via greenfield investment. Otherwise firm 2 will employ its monopoly pricing strategy.

Firm $i=1,2$ produces with constant marginal cost $c_{i}$. Production takes place without any fixed cost. The entering MNE employs a superior technology than the domestic firm $\left(c_{1}>c_{2} \geq 0\right)$. Without this assumption the results would be trivial as will become clear in what follows. But besides that, it nicely fits to the common observation that domestic firms in CEE possess less efficient technologies compared to MNEs. When entering by acquisition it is assumed that the entrant can only make use of the acquired

\footnotetext{
${ }^{3}$ However, we introduce cost asymmetry among firms to the basic Hotelling model.
} 
firm's technology $c_{1} \cdot{ }^{4}$ On the other hand, when setting up a new venture, firm 2 can obviously implement its own technology $c_{2}$.

Entry is viable if the entrant can earn a post-entry profit at least covering the cost of entry. Foreign market entry requires a substantial investment into physical capital, marketing etc., especially a greenfield entry. The cost of entry via greenfield investment is denoted by $k \geq 0$. The entry cost in case of acquisition is equal to the acquisition price because of the assumption that the entrant uses technology $c_{1}$ and does not bear any adaptation cost or restructuring cost. The acquisition price, denoted by $P_{A}$, is determined endogenously. To keep things simple it is assumed the entrant can make a take-it-or-leave-it-offer to acquire firm $1 .^{5}$

The time structure of the entry game in period 1 is the following.

At stage 1, firm 2 (MNE) can choose between making a take-it-or-leave-it offer to acquire firm 1 , greenfield investment or no market entry.

At stage 2, if firm 2 has made an offer, the incumbent firm 1 can accept or reject the offer.

At stage 3, firm 2 can again choose between greenfield investment or no entry in case firm 1 has turned the offer down.

At stage 4, firms compete in prices and profits are realized.

We look for a sub-game perfect equilibrium of the bargaining game just described and therefore solve by backwards induction. If the entrant can

\footnotetext{
${ }^{4}$ It could also be assumed that the entrant can implement its own technology at a certain adaptation cost. This would not alter the results but make the model more complicated by adding extra variables. In our model, firm 2 bears some kind of adaptation cost caused by the fact that only the inferior technology can be used which in turn yields lower profits than employing the superior technology.

${ }^{5}$ The acquisition price obviously depends on the bargaining power of the entrant and the incumbent. Other bargaining solutions, where the domestic firm has some bargaining power, would lead to a higher acquisition price and therefore shift preferences of the MNE in favor of greenfield investment. The other extreme case would be a situation, as argued by Grossman and Hart [1980], where shareholders would not tender their share below the post acquisition value of the firm. Thus, the free rider problem would render the acquisition infeasible unless the acquiring firm initially holds some of the shares. Assuming full bargaining power of the entrant instead, at least constitutes a lower bound for the acquisition price.
} 
credibly commit to greenfield entry if its offer is rejected, then the acquisition price $P_{A}$ will clearly be equal to firm 1's post-greenfield profit. The entrant can only credibly commit to a greenfield entry if this yields a non-negative net profit. To put it in other words, $k$ must not be too large. Otherwise the entrant cannot commit to greenfield entry. Thus, the acquisition price will be equal to firm 1's monopoly profit in this case.

Consumers incur a linear transportation cost $t$ if they buy the good from one of the firms. The higher the transportation cost, the more differentiated are the goods and the less intense is the price competition. The parameter $t$ can be interpreted as a measure of competition intensity in the market. The larger the value of $t$, the less intense is the competition and vice versa. If $t=0$ we essentially have Bertrand competition. Each consumer wants to buy exactly one unit of the good in every period if its price is not too high. Consumers' surplus from consumption is denoted by $s$. Let $p_{i}$ denote the price charged by firm $i=1,2$. Hence, in case of a greenfield investment the net utility of a consumer located at $x$ is

$$
U= \begin{cases}s-x t-p_{1} & \text { if good is bought from firm 1 } \\ s-(1-x) t-p_{2} & \text { if good is bought from firm 2 } \\ 0 & \text { if good is not bought }\end{cases}
$$

In case of acquisition the net utility of a consumer located at $x$ becomes

$$
U= \begin{cases}s-x t-p_{2} & \text { if good is bought from firm 2 } \\ 0 & \text { if good is not bought. }\end{cases}
$$

Two additional assumptions are made concerning the consumers' surplus:

1. The consumers' surplus is sufficiently large, such that firm 2 would like to serve the entire market when using its own technology: $s \geq c_{2}+2 t$.

2. For $c_{1} \geq s$, firm 1 is not in the market from the beginning.

The first assumption excludes cases that are characterized by very weak competition intensity. Since we would like to analyze the effect of competition 
intensity these situations are of little interest. ${ }^{6}$ The second assumption is on the one hand very intuitive in that a firm operating with a loss for certain will not be in the market. ${ }^{7}$ On the other hand, it enriches the analysis by considering the observation that the entry decision is also restricted by a limited supply of potential acquisition targets. In this situation the entrant can only choose to enter the market through greenfield investment or not to enter the market at all.

As argued before, entry is viable if the post-entry profit at least covers the cost of entry. Acquisition is a better alternative than greenfield investment if the net post-entry profit of the former is higher than of the latter entry mode. In what follows we consider the effects of the models parameters on the optimal entry mode decision. The profits for the alternative entry modes and the optimal decision are determined in the Appendix.

\section{Greenfield Investment versus Acquisition}

What are the driving forces determining the optimal entry mode decision? All of the model's parameters enter into the decision function. In principle, there are three crucial values, that are essential for the decision. These values are the acquisition price, the monopoly profit in case of acquisition, and the net greenfield profit. As will be seen below, there are some fairly obvious results concerning the impact of certain parameters on these values, while others enter into the decision in a non-trivial fashion.

We now look at the different exogenous variables that affect the choice of greenfield investment versus acquisition in term. We start with considering the investment cost $k$. The investment cost is crucial for the determina-

\footnotetext{
${ }^{6}$ However, as will become clear shortly, for very weak competition intensity either greenfield investment or no entry is the optimal choice.

${ }^{7}$ In the case of state-owned firms, especially for CEE countries, it could be argued that a firm would even be in the market when making a loss for sure and the state had carried this loss. Within the assumptions of this model the entrant would never acquire such a firm. In a post-greenfield situation this firm would no longer be in the market unless the state would bear an even higher loss. This scenario is not part of our analysis.
} 
tion of the acquisition price and therefore the achievable profit under both alternative entry modes. It is straightforward to see that, as $k$ increases, acquisition becomes relatively more attractive. Surprisingly, however, if $k$ gets too large, acquisition becomes unattractive and the entrant prefers not to enter the market at all. What is the reason for this counterintuitive result? The greenfield profit $\pi_{2}^{G}$ is strictly decreasing in $k$. Note that for a certain investment cost $k=\bar{k}$ this profit becomes equal to zero. Thus, for $k \geq \bar{k}$ greenfield investment is no longer viable. This results in an acquisition price equal to firm 1's monopoly profit. Therefore, acquisition has no advantage over no entry and the entrant chooses not to enter at all. This result is summarized in the following proposition. ${ }^{8}$

Proposition 1 There exists a $\bar{k}\left(s, c_{1}, c_{2}, t\right)$, such that for $k<\bar{k}$ an increase in $k$ makes acquisition more attractive relative to greenfield investment. For $k \geq \bar{k}$ the entrant prefers not to enter at all.

This result is surprising on first sight since it states, that acquisition really only is an option for market entry, if a greenfield entry is also profitable. In other words market entry will be an optimal decision only if greenfield investment would be viable. ${ }^{9}$

How does the technology parameter $c_{1}$ affect the mode of entry decision? Since the entrant can, in case of acquisition, only make use of the inferior technology $c_{1}$, this production cost directly influences all crucial values. This means $c_{1}$ has an effect on the acquisition price $P_{A}$, the monopoly profit in case of acquisition $\pi_{1}^{M}$ and the greenfield profit $\pi_{2}^{G} \cdot{ }^{10}$ A priori one might expect, that an increase in $c_{1}$ makes greenfield investment relatively more attractive compared to acquisition since the monopoly profit decreases, while the greenfield profit increases. On the other hand, the acquisition price also decreases in $c_{1}$.

\footnotetext{
${ }^{8}$ See also Figure 1 in the Appendix which highlights the optimal decision for certain parameter values. The dotted line in the bottom area displays $\bar{k}$.

${ }^{9}$ See Appendix for an exact determination of $\bar{k}$ in the different parameter cases.

${ }^{10}$ The subscript 1 for the monopoly profit in case of acquisition indicates that technology $c_{1}$ is used.
} 
Lemma 1 Increasing $c_{1}$ has a strictly positive effect on the greenfield profit $\pi_{2}^{G}$, a non-positive effect on the acquisition price $P_{A}$, and a strictly negative effect on the monopoly profit $\pi_{1}^{M}$ :

$$
\frac{d \pi_{2}^{G}}{d c_{1}}>0 ; \frac{d P_{A}}{d c_{1}} \leq 0 ; \frac{d \pi_{1}^{M}}{d c_{1}}<0 .
$$

Proof: See Appendix.

The positive effect on the greenfield profit is very intuitive since increasing the production cost for the incumbent leads to an improved position for the entrant in competition. Also there is certainly a non-positive effect on the acquisition price as well as a negative one on the monopoly profit. From the point of view of the entrant, a more inferior competitive position of the incumbent makes greenfield investment more attractive. On the other hand, acquisition gets cheaper since the acquisition price (weakly) decreases, but at the same time the gross profit in case of acquisition $\pi_{1}^{M}$ strictly decreases. A priori it is not clear if (and which) one of the effects on the crucial values dominates. However, there is an unambiguous tendency, as the following lemma states.

Lemma 2 The effect of an increase in $c_{1}$ on the monopoly profit $\pi_{1}^{M}$ (weakly) dominates the effect on the acquisition price $P_{A}$ and therefore the net acquisition profit $\pi_{2}^{A}$ (weakly) decreases in $c_{1}$ :

$$
\left|\frac{d \pi_{1}^{M}}{d c_{1}}\right| \geq\left|\frac{d P_{A}}{d c_{1}}\right| \Leftrightarrow \frac{d \pi_{2}^{A}}{d c_{1}} \leq 0 .
$$

Proof: See Appendix.

The effect on the acquisition price $P_{A}$ is equal to the effect on the gross profit $\pi_{1}^{M}$ only in Case 3 (b), since then both values are equal. In all other cases the latter effect strictly dominates the former. Therefore, except for the case in which acquisition and no entry yield the same profit, the acquisition profit strictly decreases in $c_{1}$. Given these results the following proposition can be claimed. ${ }^{11}$

\footnotetext{
${ }^{11}$ See Figure 1 in the Appendix for an illustration of the result.
} 
Proposition 2 For $k<\bar{k}$ there exists a $\bar{c}_{1}\left(s, c_{2}, t, k\right)$, such that

(a) for $c_{1} \leq \bar{c}_{1}$ acquisition is the optimal mode of entry and

(b) for $c_{1}>\bar{c}_{1}$ greenfield investment is the optimal mode of entry.

Proof: See Appendix.

For very similar technologies $\left(c_{1} \leq \bar{c}_{1}\right)$ it is obvious that acquisition is always favorable over a greenfield investment, since then greenfield investment leads to a relatively low profit for the entrant, while the achievable monopoly profit using technology $c_{1}$ is high. When increasing $c_{1}$ for a given $c_{2}$, and therefore increasing the technology difference, Lemma 2 applies. Thus, for sufficiently different technologies, greenfield investment is the optimal mode of entry. At the same time the investment cost $k$ should not be too large, since it directly reduces the net profit for greenfield entry.

Next, we consider the effect of the consumers' surplus $s$ on the decision of entry mode. This variable naturally has an impact on the profits that can be achieved. Obviously, the monopoly profit should increase in the value of $s$. On the other hand, one could expect the greenfield profit and the acquisition price to react in the same manner. However, as the following lemma shows this is not in general the case.

Lemma 3 Increasing s results in

(i) a strictly positive effect on the monopoly profit $\pi_{1}^{M}$ and a (weakly) positive effect on the acquisition profit $\pi_{2}^{A}$,

$$
\frac{d \pi_{1}^{M}}{d s}>0 ; \frac{d \pi_{2}^{A}}{d s} \geq 0,
$$

(ii) no effect on the greenfield profit $\pi_{2}^{G}$ or the acquisition price $P_{A}$ for $s \geq \frac{1}{2}\left(c_{1}+c_{2}+3 t\right)$,

$$
\frac{d \pi_{2}^{G}}{d s}=0 ; \frac{d P_{A}}{d s}=0,
$$

but strictly positive effects for $s<\frac{1}{2}\left(c_{1}+c_{2}+3 t\right)$,

$$
\frac{d \pi_{2}^{G}}{d s}>0 ; \frac{d P_{A}}{d s}>0 .
$$

Proof: See Appendix. 
The following proposition describes the effect of an increase in $s$ on the decision of entry mode. ${ }^{12}$

Proposition 3 For $k<\bar{k}$ there exists a finite $\bar{s}\left(c_{1}, c_{2}, t, k\right)$, such that acquisition is the optimal mode of entry for all $s \geq \bar{s}$.

Proof: See Appendix.

The intuition behind this result is fairly simple. The higher the gross benefit for the consumers, the higher the monopoly profit becomes. On the other hand, above a certain value of $s$ the greenfield profit as well as the acquisition price are no longer affected by an increase in $s$, since these values become independent of $s{ }^{13}$ Thus, there exists a value $\bar{s}\left(c_{1}, c_{2}, t, k\right)$ above which acquisition will be strictly better than greenfield investment. But this result is only valid as long as a greenfield investment would be viable, too, i.e. $k<\bar{k}$.

The result presented in Proposition 3 is surprising since it claims that the entry mode decision depends on the consumers' surplus in an unexpected way. In particular, it implies that for two products, differing only with respect to consumers' gross benefit, in the market for one good greenfield investment might be the optimal choice, while in the other one it is acquisition. Moreover, if consumers in different regions would associate the same product with different valuations, the same effect on the entry decision could apply.

How does the optimal entry mode decision change with a change in the competition intensity $t$ ? Obviously, the effect of an increase in $t$ on the monopoly profit is always negative. The effects on the other crucial values, however, are not as clearcut. In particular, for increasing $t$ (decreasing competition intensity) the effect on the acquisition price is inverse U-shaped, while the effect on the greenfield profit and the acquisition profit is U-shaped. A priori it is not clear how these opposing effects influence the optimal entry mode choice. As one result of this we can show that under certain conditions

\footnotetext{
${ }^{12}$ Figure 2 in the Appendix highlights the results claimed in the following three propositions for certain parameter values.

${ }^{13}$ As claimed in Lemma 3. The reason for this is the equilibrium in price strategies which is independent of $s$ in Case 1 and Case 2.
} 
there is a non-monotonic relation between the competition intensity parameter $t$ and the entry decision. When considering the effect of the competition intensity again the consumers' surplus plays an important role. Two interesting results follow for different levels of consumers' benefit. We first consider a situation with a relatively high value of consumers' surplus $(s \geq \hat{s})$ and sufficiently low investment cost $(k \leq \hat{k})$. A formal definition of $\hat{s}$ and $\hat{k}$ is given in the Appendix.

Proposition 4 For $s \geq \hat{s}$ and $k \leq \hat{k}$ there exists a $\bar{t}\left(s, c_{1}, c_{2}, k\right)$, such that

(a) for $t \leq \bar{t}$ acquisition is the optimal mode of entry and

(b) for $t>\bar{t}$ greenfield investment is the optimal mode of entry.

Proof: See Appendix.

This result claims that for a sufficiently high consumers' gross benefit $s$ and investment cost $k$ not too high the optimal mode of entry is acquisition for higher competition intensities, while it is greenfield investment for low competition intensity. Thus, there exists a certain cutoff value for $t$ that determines whether one or the other entry mode constitutes an optimal choice. The first part of the result is related to Proposition 3, which stated that there exists a value $\bar{s}$, such that acquisition is the optimal mode of entry for all $s \geq \bar{s}$. We can find a value $\hat{s} \geq \bar{s}$ for high competition intensity. Decreasing the competition intensity (increasing $t$ ) for the very same value of $\hat{s}$ results in a negative effect on the net acquisition profit and a positive effect on the greenfield profit. The reason for the former effect is that a lower competition intensity results in a higher acquisition price and at the same time a lower monopoly profit. The latter effect is due to the fact that lower competition intensity results in higher profits. Further decreasing the competition intensity eventually leads to greenfield investment as the optimal choice.

The result suggests that for two different markets that are only distinguished by different levels of competition intensity, in one market acquisition may be the optimal choice, while it is greenfield investment in the other. This provides another possible explanation as for why entry modes should differ for entry into different markets. 
Now we come to the second result concerning the effect of the competition intensity for lower values of $s$. The following proposition shows that the competition intensity, surprisingly, has a non-monotonic impact on the entry mode decision.

Proposition 5 For $s \in(\underline{s}, \tilde{s})$ and $k \in\left(\frac{1}{3}\left(c_{1}-c_{2}\right), \frac{3}{5}\left(c_{1}-c_{2}\right)\right]$ there exist $\underline{t}\left(s, c_{1}, c_{2}, k\right)$ and $\tilde{t}\left(s, c_{1}, c_{2}, k\right)$, such that the optimal entry mode is

(a) greenfield investment for very intense competition, $t \leq \underline{t}$,

(b) acquisition for intermediate competition intensities, $t \in(\underline{t}, \tilde{t})$, and

(c) greenfield investment for low competition intensity, $t \geq \tilde{t}$,

where $\underline{s}=c_{1}+2 \sqrt{\frac{1}{3}\left(c_{1}-c_{2}\right)\left(\frac{2}{3}\left(c_{1}-c_{2}\right)-k\right)}$ and $\tilde{s}=2 c_{1}-c_{2}-k$.

Proof: See Appendix.

The proposition shows that under certain conditions the competition intensity affects the optimal entry mode decision in a non-monotonic fashion. ${ }^{14}$ Greenfield investment is the prefered mode of entry, when the market is very much or very little competitive. For intermediate values acquisition is the optimal entry mode. To understand the intuition for this interesting result we will consider the effects of competition on the three crucial values, i.e. the acquisition price, the monopoly profit, and the greenfield profit.

If competition is very fierce, the acquisition price is equal to zero and at the same time the greenfield profit is large. The reason for this is that by greenfield investment MNE is be able to force the incumbent firm out of the market because of the technological advantage it possesses. The monopoly profit is comparably low because of the assumed low consumer surplus and the restriction to the inferior technology. Therefore, greenfield investment is the optimal entry mode even though acquisition comes at a price of zero. For intermediate values the acquisition price is still very small. But the

\footnotetext{
${ }^{14}$ For $k>\frac{3}{5}\left(c_{1}-c_{2}\right)$ there can even exist - at least for some $s$ within the interval a $\hat{t}\left(s, c_{1}, c_{2}, k\right)$ such that for $t \in(\tilde{t}, \hat{t})$ greenfield investment is the optimal choice and for $t \geq \hat{t}$ it is no entry.
} 
greenfield profit becomes much smaller since with less intense competition the MNE can no longer force the incumbent out of the market. The monopoly profit remains almost the same. Thus, acquisition becomes the optimal mode of entry. When the market is very little competitive, greenfield investment again becomes the optimal entry mode. The reason for this is that the firms achieve more power over their consumers and therefore larger profits. As a consequence the acquisition price as well as the greenfield profit increase.

To summarize the described effects of competition for low consumers' surplus, we can argue that it is more important to use the superior technology than to become a monopolist when the market is very little or very much competitive and vice versa for intermediate values.

\section{Discussion and Conclusions}

Although highly stylized the model presented above gives some useful new insight into the determinants that affect the strategic choice of entry mode. Our contribution to the literature on foreign entry is to establish a theoretical framework that allows an in-depth analysis of the impact of various exogenous factors in a simple setting. In particular, we are able to specify exactly how the market structure and the competition intensity in a market influence the entry decision. Even though previous work already identified both as important factors, it was not able to characterize their exact impact. While our analysis does so, it moreover shows that the influence of these factors is not as straightforward as the literature suggests.

In principle, there exist three crucial values that determine the optimal entry choice: The acquisition price, the monopoly profit when using the inferior technology, and the net greenfield profit. We examined the different exogenous variables specified in the model that affect these values.

First, we considered the cost associated with greenfield entry. Intuitively, it could be argued that increasing this cost leads to acquisition becoming more attractive. We showed that an increasing investment cost has this effect only up to a certain point. If the cost gets too large, however, acquisition 
becomes unattractive and the entrant prefers not to enter the market at all.

Second, for the technology parameter of the domestic competitor, the effect on the entry decision was a priori not clear since it has opposite effects on the three crucial values already mentioned. An increase in the production cost of the domestic firm has a positive effect on the entrants greenfield profit, but negative effects on the monopoly profit and the acquisition price. Nevertheless, we could show that the effect on the monopoly profit dominates the effect on the acquisition price. Therefore, greenfield investment becomes the optimal mode of entry if the difference in technological capabilities is sufficiently large.

Third, the gross benefit for the consumers definitely has an impact on the decision since it determines how much rents can be extracted from them. The higher this benefit, the higher should become the achievable profits under both entry modes. We showed that for a given constellation of the other variables there exists a finite value for consumers' surplus such that acquisition is the optimal mode of entry for all higher values. The reason for this result is that the greenfield profit increases in the consumers benefit only up to a certain point, but beyond it remains the same. As soon as it comes to a situation where both firms cannot act as local monopolists their profits in competition remain the same for all higher values of consumers' surplus. The result implies that, for two different product markets that are only distinguished by different levels of consumers' surplus, it may well be the case that in one market greenfield investment is the optimal mode, while in the other one it is acquisition. This implication can help to explain why MNEs in some markets employ the greenfield entry strategy and in others acquisition entry, while in either both opportunities are present.

Fourth, the competition intensity in a market was characterized as one of the most important factors concerning the decision of entry mode. There are two situations to be distinguished, depending on consumers' surplus. For a sufficiently high consumers' surplus we found that high competition intensity leads to acquisition as the optimal mode of entry, but it is greenfield investment for low levels of competition. The reason for this result is that the acquisition price and the greenfield profit increase with decreasing competi- 
tion, while the monopoly profit decreases. Less intensive competition results in a reduced incentive to become a monopolist, while the technological advantage becomes more important. More surprisingly, however, we found that the optimal mode of entry depends on the competition intensity in a nonmonotonic fashion, when consumers' surplus is relatively low. Greenfield investment is the optimal mode of entry, when the market is very much or very little competitive, while it is acquisition for intermediate values. This is caused by the fact that for lower consumers' surplus it becomes more important to use the superior technology when the market is very much or very little competitive, while it becomes more important to be a monopolist in the intermediate case.

The present general analysis sheds some light on the empirical evidence on the choice of foreign entry mode that has been provided recently. In particular, we can give some explanation for the on first sight counterintuitive observations for entry into countries in Central and Eastern Europe. The empirical evidence suggests that these countries are characterized by specific conditions for competition that differ from other markets.

Greenfield investment is the most common mode of entry into CEE as Meyer [1998] derives from his data set. This is a surprising fact since there is a recent trend towards acquisition worldwide observed. One possible explanation could be that CEE countries lack potential acquisition targets for those industries where greenfield investment took place. We provided other additional explanations in the present paper. We showed that greenfield investment is an optimal choice if the local competitor possesses an inferior technology. Since it is a common fact that firms in CEE do not have access to state of the art technology, our model gives a nice explanation for the observed situation. Moreover, our results characterize the exact market conditions under which greenfield investment is the optimal mode of entry.

Entry into fast-growing industries in CEE, surprisingly, takes place via greenfield investment, but not via acquisition. Intuitively, it should be argued that, since the speed of entry is important in industries that are fast-growing, acquisition should be prefered. Acquisition certainly provides a faster entry and access to a market than greenfield investment. Again, it could be ar- 
gued that the technological backwardness of domestic firms is the reason for the counterintuitive behavior. Meyer [1998] suggests as possible explanations that either the investment itself is the cause for the growth in the industry, or growing industries can accommodate more entrants without frictions between competitors, or the highest growth occurred in until then neglected industries. We showed that greenfield investment is an optimal choice if the competition intensity is low. Since for fast-growing industries it is reasonable to assume a low competition intensity, this provides an alternative explanation for the empirical observation.

A possible extension of the model could be to include the entry decision of more than one MNE, either simultaneously or sequentially. Despite this we feel confident that the assumptions and conclusions of our model are relevant for the entry mode decision and leave other considerations for future research. 


\section{Appendix}

\section{A) The equilibria in price strategies}

In order to compute the profits for the alternative entry modes, the equilibria in price strategies have to be defined for the different situations. When firm 2 enters via acquisition it will afterwards employ its monopoly pricing strategy using technology $c_{1}$. That is $p_{2}^{M}=s-t$ for $s \geq c_{1}+2 t$ or $p_{2}^{M}=\frac{s+c_{1}}{2}$ otherwise. In case of greenfield investment the equilibrium price strategies are:

- For $c_{1} \geq s$ firm 1 is not in the market and thus firm 2 chooses $p_{2}^{M}=s-t$.

- Case 1: $p_{1}=c_{1}, \quad p_{2}=c_{1}-t$.

- Case 2: $p_{1}=\frac{2 c_{1}+c_{2}+3 t}{3}, \quad p_{2}=\frac{2 c_{2}+c_{1}+3 t}{3}$.

- Case 3: (a) $p_{1}=s-\frac{c_{2}-c_{1}+3 t}{6}, p_{2}=s-\frac{c_{1}-c_{2}+3 t}{6}$.

(b) $p_{1}^{M}=\frac{s+c_{1}}{2}, \quad p_{2}=\frac{3 s-2 t-c_{1}}{2}$.

The first two cases display the common equilibrium price strategies in a model of horizontal product differentiation. In Case 1 firm 2 can force the incumbent out of the market and then faces all demand. In Case 2 there exists a consumer with location $\tilde{x}$, who is indifferent between buying from firm 1 or firm 2. In Case 3 things get a bit more complicated. The reason for this is the assumed situation with constant but asymmetric marginal cost for the two parties and the assumption that firm 2 would in principle like to serve the whole market when using its own technology $c_{2}$. On the other hand, there is no restriction on the technological capabilities of firm 1 and therefore Case 3 emerges as a possible situation. The distinction between Case 3 (a) and $(b)$ is that in the former firm 1's monopoly supply is greater than $\tilde{x}$ and in the latter it is smaller. The defined equilibria are not unique, since there exists a continuum of equilibria in an $\epsilon$-environment close to them. Its range depends on the exact constellation of parameters. However, the price strategy combinations considered here always constitute an equilibrium for each case. Furthermore, it easily can be shown, that the pricing strategies for case (a) cannot be an equilibrium for case (b). 


\section{B) Profits for the alternative entry modes}

If firm 2 chooses to enter via greenfield investment its profit is determined by the outcome of competition with the domestic firm net of the investment cost $k$. On the other hand, if the firm enters via acquisition the profit is determined by the monopoly profit when using the inferior technology $c_{1}$ net of the acquisition price $P_{A}$. As argued before this acquisition price depends on the ability of firm 2 to commit to greenfield entry in case its take-itor-leave-it offer is turned down. If the firm can commit to greenfield entry the acquisition price is equal to firm 1's post greenfield value - the profit that can be achieved in competition with the MNE. Otherwise if the MNE cannot commit to greenfield entry the acquisition price is equal to firm 1's monopoly profit. The results derived for acquisition entry assume that firm 2 can commit to greenfield entry. Otherwise firm 2 prefers not to enter.

\section{Greenfield investment}

For $c_{1} \geq s$ firm 1 is not in the market. Thus, firm 2's profit becomes

$$
\pi_{2}^{G}=s-t-c_{2}-k .
$$

Next, the situation is considered where firm 1 is in the market, that is $s>c_{1}$. At this point three case have to be distinguished: 1 . If the price difference between the two firms exceeds $t$ along the whole interval, one firm has no demand. 2. Otherwise both firms face a demand if $s$ is sufficiently large, such that all consumers want to buy one unit of the good. 3. Both firms possess local monopoly power if $s$ is not sufficiently large.

Case 1: Within the assumptions of this model there is only one case to be considered, namely firm 2 facing all demand, $p_{1}-p_{2}>t .{ }^{15}$ The firms' profits are

$$
\begin{aligned}
& \pi_{1}^{G}=0, \\
& \pi_{2}^{G}=c_{1}-c_{2}-t-k .
\end{aligned}
$$

\footnotetext{
${ }^{15}$ After inserting the equilibrium price strategies for Case 2 it follows that $p_{1}-p_{2}>$ $t \Leftrightarrow t<\frac{c_{1}-c_{2}}{3}$.
} 
Case 2: The price difference between the two firms does not exceed $t$, that is $p_{1}-p_{2} \leq t$, and $s$ is sufficiently large. ${ }^{16}$ Thus, the firms' profits are

$$
\begin{aligned}
& \pi_{1}^{G}=\frac{\left(c_{2}-c_{1}+3 t\right)^{2}}{18 t}, \\
& \pi_{2}^{G}=\frac{\left(c_{1}-c_{2}+3 t\right)^{2}}{18 t}-k .
\end{aligned}
$$

The consumers' surplus $s$ is sufficiently large if $s \geq \frac{1}{2}\left(c_{1}+c_{2}+3 t\right)$. Thus, there exists a consumer with location $\tilde{x}$ who is indifferent between buying from firm 1 and buying from firm $2 .{ }^{17}$

Case 3: For $s<\frac{1}{2}\left(c_{1}+c_{2}+3 t\right)$ the consumer with location $\tilde{x}$, who would have been indifferent between the two firms, would not buy if the firms were to choose the competitive prices. Thus, both firms possess local monopoly power. Depending on consumers' surplus two more cases have to be distinguished: (a) The pricing strategies constitute an equilibrium such that the consumer located at $\tilde{x}$ is indifferent between the firms and between buying or not. (b) Firm 1 sets the monopoly price and firm 2 sets a price such that there exists a consumer who is indifferent from which firm to buy and whether or not to buy at all.

(a) For $s>\frac{1}{3}\left(2 c_{1}+c_{2}+3 t\right)$ firms' profits are

$$
\begin{aligned}
& \pi_{1}^{G}=\left(\frac{6 s-5 c_{1}-c_{2}-3 t}{6}\right)\left(\frac{c_{2}-c_{1}+3 t}{6 t}\right), \\
& \pi_{2}^{G}=\left(\frac{6 s-c_{1}-5 c_{2}-3 t}{6}\right)\left(\frac{c_{1}-c_{2}+3 t}{6 t}\right)-k .
\end{aligned}
$$

(b) For $\frac{1}{3}\left(2 c_{1}+c_{2}+3 t\right) \geq s$ firms profits' are

$$
\begin{aligned}
& \pi_{1}^{G}=\frac{\left(s-c_{1}\right)^{2}}{4 t} \\
& \pi_{2}^{G}=\left(\frac{3 s-c_{1}-2 c_{2}-2 t}{2}\right)\left(\frac{2 t+c_{1}-s}{2 t}\right)-k .
\end{aligned}
$$

\footnotetext{
${ }^{16}$ After inserting the equilibrium prices it follows that $p_{1}-p_{2} \leq t \Leftrightarrow t \geq \frac{c_{1}-c_{2}}{3}$.

${ }^{17}$ Where $\tilde{x}=\frac{p_{2}-p_{1}+t}{2 t}=\frac{c_{2}-c_{1}+3 t}{6 t}$.
} 


\section{Acquisition}

For $c_{1} \geq s$ acquisition is not feasible since by assumption there exists no target firm. For $s>c_{1}$ the same three cases as above have to be considered. To calculate firm 2's net profit, its monopoly pricing strategy also has to be taken into account. For $s \geq c_{1}+2 t$ the monopolist would like to serve the whole market and otherwise only a part of it.

Case 1: For $t<\frac{c_{1}-c_{2}}{3}$ the acquisition price $P_{A}$ will be zero.

1. For $s \geq c_{1}+2 t$ firm 2 's profit is

$$
\pi_{2}^{A}=s-t-c_{1}
$$

2. For $s<c_{1}+2 t$ the profit is

$$
\pi_{2}^{A}=\frac{\left(s-c_{1}\right)^{2}}{4 t}
$$

Case 2: For $t \geq \frac{c_{1}-c_{2}}{3}$ and $s$ being sufficiently large, that is $s \geq \frac{1}{2}\left(c_{1}+c_{2}+3 t\right)$, the acquisition price will be $P_{A}=\frac{\left(c_{2}-c_{1}+3 t\right)^{2}}{18 t}$.

1. For $s \geq c_{1}+2 t$ the net profit of firm 2 is

$$
\pi_{2}^{A}=s-t-c_{1}-\frac{\left(c_{2}-c_{1}+3 t\right)^{2}}{18 t}
$$

2. For $s<c_{1}+2 t$ the net profit is

$$
\pi_{2}^{A}=\frac{\left(s-c_{1}\right)^{2}}{4 t}-\frac{\left(c_{2}-c_{1}+3 t\right)^{2}}{18 t}
$$

Case 3: If $s$ is not sufficiently large the acquisition price becomes in case (a) $P_{A}=\left(\frac{6 s-5 c_{1}-c_{2}-3 t}{6}\right)\left(\frac{c_{2}-c_{1}+3 t}{6 t}\right)$ and in case (b) $P_{A}=\frac{\left(s-c_{1}\right)^{2}}{4 t}$. Thus, the net profits for firm 2 in these cases are ${ }^{18}$

$$
\begin{aligned}
& \text { (a) } \pi_{2}^{A}=\frac{\left(3 s-2 c_{1}-c_{2}-3 t\right)^{2}}{36 t}, \\
& \text { (b) } \pi_{2}^{A}=0 .
\end{aligned}
$$

\footnotetext{
${ }^{18}$ If $s$ is not sufficiently large it follows $s<\frac{1}{2}\left(c_{1}+c_{2}+3 t\right)<c_{1}+2 t$. Thus, firm 2 will always only serve part of the market using technology $c_{1}$.
} 


\section{C) The optimal entry mode}

The superiority of one entry mode over the other will be written as an inequality with consumers' surplus $s$ on the left-hand side. In the borderline case when greenfield investment and acquisition yield the same net post-entry payoff, i.e. the constraint is fulfilled with equality, it is simply assumed that acquisition will be chosen.

For $c_{1} \geq s$ only greenfield investment is feasible. The entrant will choose this entry mode only if this is viable:

$$
\pi_{2}^{G}=s-t-c_{2}-k>0 .
$$

Thus, for

$$
s>c_{2}+t+k
$$

firm 2 will choose greenfield investment and otherwise it will not enter the market at all.

If firm 1 is initially in the market, i.e. $s>c_{1}$, acquisition will be chosen whenever $\pi_{2}^{A} \geq \pi_{2}^{G}$. Solving for $s$ and re-arranging gives a critical value $\bar{s}$ for each situation: ${ }^{19}$

Case 1: When firm 1 faces no demand in competition with firm 2, i.e. $t<$ $\frac{c_{1}-c_{2}}{3}$, greenfield investment is viable if $k<\bar{k}=c_{1}-c_{2}-t$.

1. For $s \geq c_{1}+2 t$ acquisition is the prefered mode of entry if

$$
s \geq \bar{s}=2 c_{1}-c_{2}-k
$$

and otherwise it is greenfield investment.

2. For $s<c_{1}+2 t$ acquisition is preferable if

$$
s \geq \bar{s}=c_{1}+2 \sqrt{t\left(c_{1}-c_{2}-t-k\right)}
$$

or greenfield investment in the opposite case.

\footnotetext{
${ }^{19}$ These values are well defined as long as $k<\bar{k}$ in the respective case.
} 
Case 2: For $t \geq \frac{c_{1}-c_{2}}{3}$ greenfield investment is viable whenever $k<\bar{k}=$ $\frac{\left(c_{1}-c_{2}+3 t\right)^{2}}{18 t}$.

1. For $s \geq c_{1}+2 t$ acquisition is the prefered mode of entry if

$$
s \geq \bar{s}=\frac{\left(c_{1}-c_{2}\right)^{2}}{9 t}+2 t+c_{1}-k
$$

and greenfield otherwise.

2. For $s<c_{1}+2 t$ acquisition is preferable if

$$
s \geq \bar{s}=c_{1}+2 \sqrt{\frac{1}{9}\left(c_{1}-c_{2}\right)^{2}+t^{2}-t k}
$$

or greenfield investment else.

Case 3: If $s$ is not sufficiently large, $s<\frac{1}{2}\left(c_{1}+c_{2}+3 t\right)$, greenfield investment is viable in case (a) if $k<\bar{k}=\left(\frac{6 s-c_{1}-5 c_{2}-3 t}{6}\right)\left(\frac{c_{1}-c_{2}+3 t}{6 t}\right)$ or in case (b) $k<\bar{k}=$ $\left(\frac{3 s-c_{1}-2 c_{2}-2 t}{2}\right)\left(\frac{2 t+c_{1}-s}{2 t}\right)$.

(a) For $s>\frac{1}{3}\left(2 c_{1}+c_{2}+3 t\right)$ acquisition is the prefered mode if

$$
s \leq \bar{s}=c_{1}+2 t-2 \sqrt{\frac{1}{9}\left(c_{1}-c_{2}\right)^{2}+\frac{1}{2} t\left(c_{1}-c_{2}+t\right)-t k}
$$

and greenfield otherwise.

(b) For $\frac{1}{3}\left(2 c_{1}+c_{2}+3 t\right) \geq s$ acquisition leads to a zero net profit for certain. If greenfield investment is not viable the MNE prefers not to enter at all. Thus, no entry will be the prefered if

$$
s \leq \bar{s}=\frac{1}{3}\left(2 c_{1}+c_{2}+4 t-\sqrt{\left(c_{1}-c_{2}+2 t\right)^{2}-12 t k}\right)
$$

and otherwise greenfield entry is viable and will be chosen. 


\section{D) $\underline{\text { Proofs }}$}

\section{Proof of Lemma 1:}

We have to show that $\frac{d \pi_{2}^{G}}{d c_{1}}>0, \frac{d P_{A}}{d c_{1}} \leq 0, \frac{d \pi_{1}^{M}}{d c_{1}}<0$ is fulfilled for all cases.

(i) Case 1: $\frac{d \pi_{2}^{G}}{d c_{1}}=1, \frac{d P_{A}}{d c_{1}}=0$.

Case 2: $\frac{d T_{2}^{G}}{d c_{1}}=\frac{c_{1}-c_{2}+3 t}{9 t}>0, \frac{d P_{A}}{d c_{1}}=\frac{c_{1}-c_{2}-3 t}{9 t} \leq 0$, for $t \geq \frac{c_{1}-c_{2}}{3}$.

Case 3: (a) $\frac{d \pi_{2}^{G}}{d c_{1}}=\frac{3 s-c_{1}-2 c_{2}-3 t}{18 t}>0, \frac{d P_{A}}{d c_{1}}=\frac{5 c_{1}-2 c_{2}-6 t-3 s}{18 t}<0$, for $s>\frac{1}{3}\left(2 c_{1}+c_{2}+3 t\right)$.

(b) $\frac{d \pi_{2}^{G}}{d c_{1}}=\frac{2 s-c_{1}-c_{2}-2 t}{2 t}>0, \frac{d P_{A}}{d c_{1}}=-\frac{s-c_{1}}{2 t}<0$, for $s \geq\left\{c_{2}+2 t, c_{1}\right\}$.

(ii) For $s \geq c_{1}+2 t$ we have $\frac{d \pi_{1}^{M}}{d c_{1}}=-1$ and $\frac{d \pi_{1}^{M}}{d c_{1}}=-\frac{s-c_{1}}{2 t}<0$ otherwise.

Q.E.D.

\section{Proof of Lemma 2:}

We have to show that $\frac{d \pi_{2}^{A}}{d c_{1}} \leq 0$ is fulfilled for all cases. Since $\frac{d \pi_{2}^{A}}{d c_{1}}=\frac{d \pi_{1}^{M}}{d c_{1}}-\frac{d P_{A}}{d c_{1}}$ it follows from proof of Lemma 1 :

Case 1: For $s \geq c_{1}+2 t$ it is $\frac{d \pi_{2}^{A}}{d c_{1}}=-1$ and $\frac{d \pi_{2}^{A}}{d c_{1}}=-\frac{s-c_{1}}{2 t}<0$ otherwise.

Case 2: For $s \geq c_{1}+2 t$ it is $\frac{d \pi_{2}^{A}}{d c_{1}}=\frac{c_{2}-c_{1}-6 t}{9 t}<0$ and $\frac{d \pi_{2}^{A}}{d c_{1}}=\frac{7 c_{1}+2 c_{2}+6 t-9 s}{18 t}<0$ otherwise.

Case 3: (a) For $s \geq \frac{1}{3}\left(2 c_{1}+c_{2}+3 t\right)$ we have $\frac{d \pi_{2}^{A}}{d c_{1}}=\frac{2 c_{1}+c_{2}+3 t-3 s}{9 t}<0$.

(b) $\frac{d \pi_{2}^{A}}{d c_{1}}=0$.

Q.E.D.

Proof of Proposition 2:

We have to show that for $k<\bar{k}$ there exists a $\bar{c}_{1}\left(s, c_{2}, t, k\right)$ such that greenfield investment is the optimal mode of entry for $c_{1}>\bar{c}_{1}$ and acquisition otherwise. Re-arranging equations (2) - (7) with $\bar{s}=s$ determines the crucial value $\bar{c}_{1}$ :

Case 1: 1 . For $s \geq c_{1}+2 t$ the crucial value is $\bar{c}_{1}=\frac{1}{2}\left(s+c_{2}+k\right)$.

2. For $s<c_{1}+2 t$ the value is $\bar{c}_{1}=s+2 t-2 \sqrt{t\left(s-c_{2}-k\right)}$. 
Case 2: 1 . For $s \geq c_{1}+2 t$ the value is $\bar{c}_{1}=\frac{1}{2}\left[2 c_{2}-9 t+3 \sqrt{t^{2}+4 t\left(s+k-c_{2}\right)}\right]$.

2. For $s<c_{1}+2 t$ it is $\bar{c}_{1}=\frac{1}{5}\left[9 s-4 c_{2}-6 \sqrt{\left(s-c_{2}\right)^{2}+5 t(t-k)}\right]$.

Case 3: (a) $\bar{c}_{1}=\frac{1}{5}\left[9 s-9 t-4 c_{2}-3 \sqrt{4\left(s-c_{2}\right)^{2}+t\left(2 s-t-2 c_{2}-20 k\right)}\right]$.

(b) $\bar{c}_{1}=2 s-2 t-c_{2}-\sqrt{\left(s-c_{2}\right)^{2}-4 t k}$.

By proofs of Lemma 1 and Lemma 2 we know that $\frac{d \pi_{2}^{G}}{d c_{1}}>0, \frac{d \pi_{2}^{A}}{d c_{1}} \leq 0$. Thus, it follows that for $c_{1}>\bar{c}_{1}$ greenfield is the optimal entry mode and acquisition otherwise. In Case 3 (b) $c_{1}>\bar{c}_{1}$ is always fulfilled by assumption $k<\bar{k}$.

Q.E.D.

Proof of Lemma 3:

We have to show that $\frac{d \pi_{1}^{M}}{d s}>0, \frac{d \pi_{2}^{A}}{d s} \geq 0$ for all cases, $\frac{d \pi_{2}^{G}}{d s}>0, \frac{d P_{A}}{d s}>0$ for $s<\frac{1}{2}\left(c_{1}+c_{2}+3 t\right)$, and $\frac{d \pi_{2}^{G}}{d s}=\frac{d P_{A}}{d s}=0$ otherwise. Note that $\frac{d \pi_{2}^{A}}{d s}=\frac{d \pi_{1}^{M}}{d s}-\frac{d P_{A}}{d s}$.

(i) For $s \geq c_{1}+2 t$ we have $\frac{d \pi_{1}^{M}}{d s}=1$ or $\frac{d \pi_{1}^{M}}{d s}=\frac{s-c_{s}}{2 t}>0$ otherwise.

(ii) Case 1: $\frac{d \pi_{2}^{G}}{d s}=\frac{d P_{A}}{d s}=0 ; \frac{d \pi_{2}^{A}}{d s}=1$ or $\frac{d \pi_{2}^{A}}{d s}=\frac{s-c_{s}}{2 t}$.

Case 2: $\frac{d \pi_{2}^{G}}{d s}=\frac{d P_{A}}{d s}=0 ; \frac{d \pi_{2}^{A}}{d s}=1$ or $\frac{d \pi_{2}^{A}}{d s}=\frac{s-c_{s}}{2 t}$.

Case 3: (a) $\frac{d \pi_{2}^{G}}{d s}=\frac{c_{1}-c_{2}+3 t}{6 t}, \frac{d P_{A}}{d s}=\frac{c_{2}-c_{1}+3 t}{6 t}>0 ; \frac{d \pi_{2}^{A}}{d s}=\frac{3 s-2 c_{1}-c_{2}-3 t}{6 t}>0$.

(b) $\frac{d \pi_{2}^{G}}{d s}=\frac{2 c_{1}+c_{2}+4 t-3 s}{2 t}>0 ; \frac{d P_{A}}{d s}=\frac{s-c_{1}}{2 t}>0 ; \frac{d \pi_{2}^{A}}{d s}=0$.

Q.E.D.

Proof of Proposition 3:

We have to show that a finite value for $\bar{s}\left(c_{1}, c_{2}, t, k\right)$ always exists when $k<\bar{k}$.

Case 1: 1. For $t \leq \frac{1}{2}\left(c_{1}-c_{2}-k\right)$ the crucial value is $\bar{s}=2 c_{1}-c_{2}-k$.

2. For $t>\frac{1}{2}\left(c_{1}-c_{2}-k\right)$ the value is $\bar{s}=c_{1}+2 \sqrt{t\left(c_{1}-c_{2}-t-k\right)}$.

Case 2: 1 . For $t \leq \frac{\left(c_{1}-c_{2}\right)^{2}}{9 k}$ the value is $\bar{s}=\frac{\left(c_{1}-c_{2}\right)^{2}}{9 t}+2 t+c_{1}-k$.

2. For $t>\frac{\left(c_{1}-c_{2}\right)^{2}}{9 k}$ the value is $\bar{s}=c_{1}+2 \sqrt{\frac{1}{9}\left(c_{1}-c_{2}\right)^{2}+t^{2}-t k}$.

Where equations $(2)$ - (5) determine the values for $\bar{s}\left(c_{1}, c_{2}, t, k\right)$. We can also determine $\bar{s}\left(c_{1}, c_{2}, t, k\right)$ in Case 3. But increasing $s$ above $s=\frac{1}{2}\left(c_{1}+c_{2}+3 t\right)$ 
always leads to the situation in Case 2, where, as shown, an $\bar{s}\left(c_{1}, c_{2}, t, k\right)$ exists whenever $k<\bar{k}$. By proof of Lemma 3 we know that $\frac{d \pi_{2}^{G}}{d s}=0$ and $\frac{d \pi_{2}^{A}}{d s}>0$ in Case 1 and Case 2. Thus, it follows that for $s \geq \bar{s}$ acquisition is the optimal entry mode. The intersection of the respective equation for $\bar{s}$ with $s=c_{1}+2 t$ or $s=\frac{1}{2}\left(c_{1}+c_{2}+3 t\right)$ determine the case distinctions.

Q.E.D.

Proof of Proposition 4:

We have to show that $\bar{t}\left(c_{1}, c_{2}, s, k\right)$ exists for $s \geq \hat{s}$ and $k \leq \hat{k}$. From proof of Proposition 3 we know that for $k<\bar{k}$ there exists an $\bar{s}$ such that acquisition is the optimal mode of entry. In Case 1 for $s \geq \hat{s}=2 c_{1}-c_{2}-k$ acquisition is the optimal entry mode. It remains to show that there exists a $\bar{t}$ in Case 2. Depending on the exact parameter constellations the crucial $\bar{t}$ is either

$$
\bar{t}_{1}=\max \left\{\frac{c_{1}-c_{2}}{3}, \frac{1}{4}\left(s-c_{1}+\frac{1}{3} \sqrt{9\left(s-c_{1}-k\right)^{2}-8\left(c_{1}-c_{2}\right)^{2}}\right)\right\}
$$

or

$$
\bar{t}_{2}=\max \left\{\frac{c_{1}-c_{2}}{3}, \frac{1}{2} k+\frac{1}{6} \sqrt{9\left(s-c_{1}\right)^{2}-4\left(c_{1}-c_{2}\right)^{2}+9 k^{2}}\right\},
$$

with $\bar{t}=\bar{t}_{1}$ for $\bar{t}_{1} \leq \frac{1}{2}\left(s-c_{1}\right)$ and $\bar{t}=\bar{t}_{2}$ otherwise. Re-arranging (4) respectively (5) yields the second part in each case.

The crucial $\bar{t}$ exists for $k \leq \hat{k}=\frac{18 s\left(c_{1}-c_{2}\right)-9\left(c_{1}^{2}-c_{2}^{2}\right)+4\left(c_{1}-c_{2}\right)^{2}}{18\left(s-c_{2}\right)}$ and $s \geq \hat{s}=$ $\max \left\{2 c_{1}-c_{2}-k, 2 c_{2}-c_{1}+2 k+\frac{1}{3} \sqrt{19\left(c_{1}-c_{2}\right)^{2}+36 k\left(c_{2}-c_{1}+k\right)}\right\}$. The intersection of $s=c_{2}+2 t$ with (6) gives a maximum value for $t$. Substituting the resulting $t$ into $s=c_{2}+2 t$ yields the second part of $\hat{s}$ which ensures that no entry never is an optimal decision in the considered situation. Rearranging $\bar{t}_{2}=\frac{1}{2} k+\frac{1}{6} \sqrt{9\left(s-c_{1}\right)^{2}-4\left(c_{1}-c_{2}\right)^{2}+9 k^{2}} \leq \frac{1}{2}\left(s-c_{2}\right)$ results in $\hat{k}$. By construction of the parameter spaces greenfield investment is the optimal mode of entry for $t>\bar{t}$ and acquisition otherwise.

Q.E.D. 
Proof of Proposition 5:

We have to show that for $s \in(\underline{s}, \tilde{s})$ and $k \in\left(\frac{1}{3}\left(c_{1}-c_{2}\right), \frac{3}{5}\left(c_{1}-c_{2}\right)\right]$ there exist $\underline{t}$ and $\tilde{t}$ with the described properties. Re-arranging (3) respectively (5) yields

$$
\begin{gathered}
\underline{t}=\frac{1}{2}\left(c_{1}-c_{2}-k-\sqrt{\left(c_{1}-c_{2}\right)^{2}-k\left(2 c_{1}-2 c_{2}-k\right)-\left(s-c_{1}\right)^{2}}\right), \\
\tilde{t}=\frac{1}{2} k+\frac{1}{6} \sqrt{9\left(s-c_{1}\right)^{2}-4\left(c_{1}-c_{2}\right)^{2}+9 k^{2}} .
\end{gathered}
$$

It is easy to show, that $\underline{t}<\frac{c_{1}-c_{2}}{3}<\tilde{t}$ for $s \in(\underline{s}, \tilde{s})$ and $k \in\left(\frac{1}{3}\left(c_{1}-c_{2}\right), \frac{3}{5}\left(c_{1}-\right.\right.$ $\left.\left.c_{2}\right)\right]$. The value for $\underline{s}$ is equal to equation (3) evaluated at $t=\frac{c_{1}-c_{2}}{3}$ and $\tilde{s}$ is equal to $\hat{s}$ in Case 1 as described in Proposition 4 . For $(\underline{s}, \tilde{s})$ not to be empty it must be that $k>\frac{c_{1}-c_{2}}{3}$. At the same time no entry should never be an optimal choice in the considered situation. Therefore, $k$ should be small enough such that $\underline{s} \geq 2 c_{2}-c_{1}+2 k+\frac{1}{3} \sqrt{19\left(c_{1}-c_{2}\right)^{2}+36 k\left(c_{2}-c_{1}+k\right)}$ is fulfilled. This value has already been determined in proof of Proposition 4. Re-arranging yields $k \leq\left(\frac{1}{72} A-8 \frac{4}{9} \frac{1}{A}+\frac{4}{9}\right)\left(c_{1}-c_{2}\right)$ with $A=(11348+$ $276 \sqrt{4641})^{\frac{1}{3}}$. Thus, the upper bound for $k$ is approximately $\tilde{k} \approx \frac{3\left(c_{1}-c_{2}\right)}{5}$, with $\tilde{k}<\left(\frac{1}{72} A-8 \frac{4}{9} \frac{1}{A}+\frac{4}{9}\right)\left(c_{1}-c_{2}\right)$.

Q.E.D. 


\section{E) Illustration of the results}

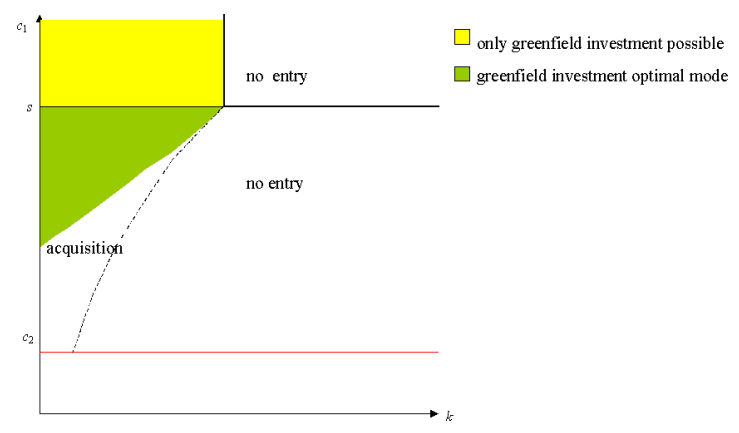

Figure 1: Optimal entry mode for $s=5, c_{2}=1, t=1$.

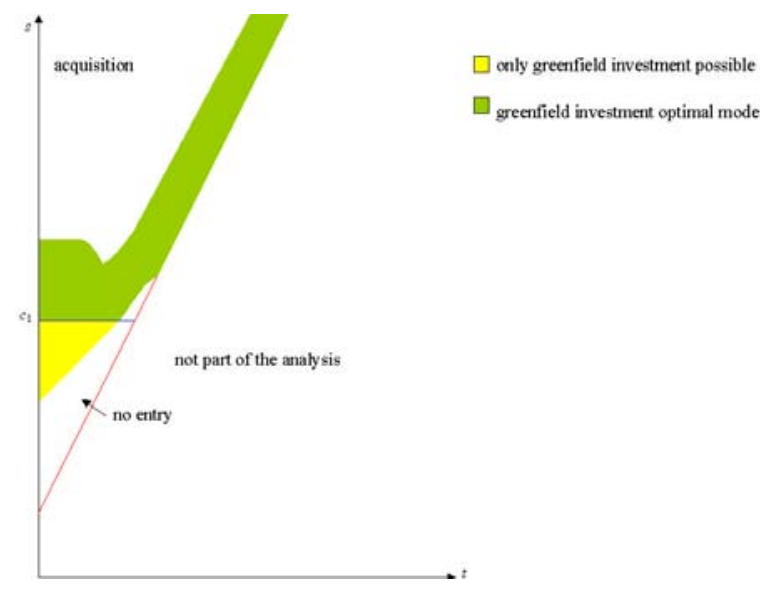

Figure 2: Optimal entry mode for $c_{1}=4, c_{2}=1, k=1.75$. 


\section{References}

Anderson, E., And H. Gatignon [1986], "Modes of Foreign Entry: A Transaction Cost Analysis and Propositions", Journal of International Business Studies, 17(3), 1 - 26.

Andersson, Th., And R. Svensson [1994], "Entry Modes for Direct Investment Determined by the Composition of Firm-Specific Skills", Scandinavian Journal of Economics, 96(4), 551 - 560.

Buckley, P.J., AND M.C. CAsson [1998], "Analyzing Foreign Market Entry Strategies: Extending the Internalization Approach", Journal of International Business Studies, 29(3), 539 - 561.

Caves, R.E., And S.K. Menra [1986], "Entry of Foreign Multinationals into U.S. Manufacturing Industries", In: Porter, M.E. (ed.): Competition in Global Industries. Boston: HBS Press. 449 - 481.

Estrin, S., K. Hughes, And S. Todd [1997], "Foreign Direct Investment in Central and Eastern Europe", London: Cassell.

GörG, H. [2000], "Analysing Foreign Market Entry: The Choice between Greenfield Investment and Acquisitions", Journal of Economic Studies, $27(3), 165-181$.

Grossman, S., And O. Hart [1980], "Takeover Bids, the Free-RiderProblem and the Theory of the Corporation", Bell Journal of Economics, 11, $42-62$.

Hennart, J.-F., And Y.-R. PARK [1993], "Greenfield vs. Acquisition: The Strategy of Japanese Investors in the United States", Management Science, 39(9), 1054 - 1070.

Hill, C.W.L., P. Hwang, And W.C. Kim [1990], "An Eclectic Theory of the Choice of International Entry Mode", Strategic Management Journal, 11, 117 - 128. 
Horn, H., And L. Persson [2001a], "The Equilibrium Ownership of an International Oligopoly", Journal of International Economics, 53(2), $307-333$.

Horn, H., And L. Persson [2001b], "Endogenous Mergers in Concentrated Markets", International Journal of Industrial Organization, 19(8), $1231-1244$.

Hotelling, H. [1929], "The Stability of Competition", Economic Journal, $39,41-57$.

Kogut, B., And H. Singh [1988], "The Effect of National Culture on the Choice of Entry Mode", Journal of International Business Studies, 19(1), $411-432$.

MeYer, K.E.E. [1998], "Direct Investment in Economies in Transition", New Horizons in International Business series, Cheltenham, U.K. and Northampton, MA, USA: Elgar.

UNCTAD [2000], "Cross-border Mergers and Acquisitions and Development", World Investment Report 2000, New York and Geneva.

ZeJan, M.C. [1990], "New Ventures or Acquisitions: The Choice of Swedish Multinational Enterprises", Journal of Industrial Economics, 38(3), $349-355$. 